\title{
Re-Emergence of Salmonellosis in Hog Farms: Outbreak and Bacteriological Characterization
}

\author{
Mariana Meneguzzi ${ }^{1}$, Caroline Pissetti ${ }^{2}{ }^{(0)}$, Raquel Rebelatto ${ }^{3}{ }^{(1)}$, Julian Trachsel ${ }^{4}$, Suzana Satomi Kuchiishi ${ }^{5}$, \\ Adrienny Trindade Reis ${ }^{6}$, Roberto Maurício Carvalho Guedes ${ }^{7}$, Joice Aparecida Leão ${ }^{8}$, Caroline Reichen ${ }^{1}$ and \\ Jalusa Deon Kich ${ }^{3, *}$
}

check for updates

Citation: Meneguzzi, M.; Pissetti, C. Rebelatto, R.; Trachsel, J.; Kuchiishi, S.S.; Reis, A.T.; Guedes, R.M.C.; Leão, J.A.; Reichen, C.; Kich, J.D. Re-Emergence of Salmonellosis in Hog Farms: Outbreak and Bacteriological Characterization. Microorganisms 2021, 9, 947. https://doi.org/10.3390/ microorganisms 9050947

Academic Editor: María-Jesús Grilló

Received: 28 March 2021

Accepted: 25 April 2021

Published: 27 April 2021

Publisher's Note: MDPI stays neutral with regard to jurisdictional claims in published maps and institutional affiliations.

Copyright: (c) 2021 by the authors. Licensee MDPI, Basel, Switzerland. This article is an open access article distributed under the terms and conditions of the Creative Commons Attribution (CC BY) license (https:/ / creativecommons.org/licenses/by/ $4.0 /)$.
1 Curso de Medicina Veterinária, Instituto Federal Catarinense, Concórdia 89703-720, SC, Brazil; meneg009@umn.edu (M.M.); carolzinha_vet@hotmail.com (C.R.)

2 Departamento de Medicina Veterinária Preventiva, Faculdade de Veterinária, Universidade Federal do Rio Grande do Sul, Porto Alegre 91540-000, RS, Brazil; carolpissetti@gmail.com

3 Embrapa Suínos e Aves, Empresa Brasileira de Pesquisa Agropecuária, Concórdia 89715-899, SC, Brazil; raquel.rebelatto@embrapa.br

4 National Animal Disease Center, Food Safety and Enteric Pathogens, Ames, IA 50010, USA; julian.trachsel@usda.gov

5 Centro de Diagnóstico de Sanidade Animal, CEDISA, Concórdia 89715-899, SC, Brazil; suzana@cedisa.org.br

6 Centro de Diagnóstico e Monitoramento Animal, CDMA, Belo Horizonte 30411-191, MG, Brazil; adrienny@cdmalaboratorio.com.br

7 Departamento de Clínica e Cirurgia Veterinária, Escola de Veterinária, Universidade Federal de Minas Gerais, Belo Horizonte 31270-901, MG, Brazil; guedes@ufmg.br

8 Laboratório Integralab, Cascavel 85816-430, PR, Brazil; joiceleao.lab@gmail.com

* Correspondence: jalusa.kich@embrapa.br; Tel.: +55-(49)-3441-0419

Abstract: Clinical salmonellosis has been increasing significantly in Brazil in recent years. A total of 130 outbreaks distributed among 10 swine-producing states were investigated. One representative Salmonella isolate from each outbreak was characterized through serotyping, antimicrobial resistance profiles, PFGE, and WGS. From 130 outbreaks: 50 were enteric, 48 were septicemic, 17 cases were characterized as hepato-biliary invasive, 13 as nodal and two were not classified. The most prevalent serovars were a monophasic variant of $S$. typhimurium (55/130), Choleraesuis (46/130), and Typhimurium (14/130). Most of the strains (86.92\%) demonstrated a high rate of multi-drug resistance. The identification of a major Choleraesuis clonal group in several Brazilian states sharing the same resistance genes suggested that these strains were closely related. Six strains from this clonal group were sequenced, revealing the same ST-145 and 11 to 47 different SNPs. The detected plasmid type showed multiple marker genes as RepA_1_pKPC-CAV1321, the first to be reported in Salmonella. All AMR genes detected in the genomes were likely present on plasmids, and their phenotype was related to genotypic resistance genes. These findings reveal that salmonellosis is endemic in the most important pig-producing states in Brazil, emphasizing the need to make data available to aid in reducing its occurrence.

Keywords: Salmonella; swine; PFGE; MLST; WGS

\section{Introduction}

Intensive pig farming production favors the emergence and re-emergence of swine diseases, resulting in poor animal performance and exerting a high economic impact. Salmonella, a gram-negative bacterium belonging to the Enterobacterales order, is an example of a costly pathogen for the swine industry and a threat to public health. It was estimated to cost producers an additional EUR 1.55 to for each pig with salmonellosis, due to reductions in daily weight gain and therapy expenses [1].

The Salmonella genus is divided into two species: Salmonella enterica and Salmonella bongori. Salmonella enterica is most often associated with foodborne illness, more than 
2600 serovars have already been described [2] and many of these have been considered important zoonotic pathogens [3]. In pigs, clinical salmonellosis is most often associated with two clinical presentations: septicemic, caused by the host-adapted serovar Choleraesuis, and severe enteritis due to the ubiquitous serovar Typhimurium. The enteric clinical presentation caused by S. typhimurium is characterized by watery diarrhea and enterocolitis during the grower-finisher phases [4]. A portion of infected animals become carriers of S. typhimurium and shed the bacterium when stressed [5]. Contamination of pork with Salmonella occurs when carcasses have contact with feces during slaughter. S. typhimurium and other similar serovars are well-recognized foodborne pathogens in humans [4].

A monophasic variant of $S$. typhimurium, with its antigenic formula 4,[5],12:i:-, has emerged as an important multi-resistant serovar commonly found in pig and pork products $[6,7]$. In Brazil, this variant has been isolated in humans and non-human sources [8,9]. In the USA, a monophasic variant of S. typhimurium has been isolated from clinical samples and further investigated for its ability to cause disease in swine, similar to $S$. typhimurium $[10,11]$.

The Salmonella serovar Choleraesuis is adapted to pigs, but is not host restricted, being able to cause extraintestinal infections in humans [12]. In pigs, S. choleraesuis usually causes septicemia, characterized by lethargy, lack of appetite, fever, cyanosis of extremities and the abdomen [4]. During the 1950s and 1960s, S. choleraesuis was the most frequently serovar isolated [13]. However, its prevalence has decreased over the years. Recent reports have associated S. choleraesuis with outbreaks in Japanese pig herds during 2001 and 2005 and in Danish pig herds during 2012 and 2013 [14,15] and in wild boar populations in several European countries [16-19].

The treatment and control of salmonellosis in pigs rely heavily on antimicrobial agents. The injudicious use of antimicrobials has raised concerns associated with the emergence of multi-drug resistant bacteria. In 2019, the World Health Organization (WHO) considered antimicrobial resistance (AMR) one of the top 10 global public health threats facing humanity. AMR affects our ability to control and treat bacterial infections in humans and animals [20].

Brazil is the fourth largest pork producer and exporter globally [21] and salmonellosis was not considered a major concern for Brazilian swine producers until 2012. However, the number of clinical cases on pig farms has grown considerably since then. Reports from international scientific meetings have described clinical cases of salmonellosis, specifically related to the septicemic form of the disease caused by Salmonella serovar Choleraesuis [22,23], raising the alarm for the swine industry and veterinarians.

Understanding the epidemiological relationships among Salmonella strains from different areas can provide valuable information towards reducing its occurrence [24,25] by enabling the implementation of specific tools in the appropriate phase of pig production. Considering the clinical importance coupled with the lack of available epidemiological data, the present study characterized 130 salmonellosis outbreaks from different states of Brazil. Therefore, the specific aims of this study were to determine the geographic outbreak distribution; serovar distribution according to farming phase and clinical-pathological presentation; antimicrobial resistance characterization; diversity of Salmonella subtypes and its epidemiological relationship.

\section{Materials and Methods}

One hundred and thirty clinical salmonellosis events diagnosed in 10 Brazilian states (Bahia-BA, Distrito Federal-DF, Goiás-GO, Mato Grosso do Sul-MS, Mato Grosso-MT, Minas Gerais-MG, Paraná-PR, Rio Grande do Sul-RS, Santa Catarina-SC, São Paulo-SP) from 2011 to 2017 were studied. Salmonella bacteriological isolation was carried out by four veterinary laboratories using their own protocols and investigating samples according to clinical and pathological findings. The isolates were obtained from different clinical samples, as described in Table S1 (see Table S1: Supplementary material). Field information and an isolate of Salmonella representative of each outbreak were consigned to Embrapa 
Swine and Poultry and deposited in the Collection of Microorganisms of Interest for Swine and Poultry (CMISEA).

\subsection{Field Information}

A database including geographical location, year of occurrence, farming stage, and site of isolation were used to provide autochthonous epidemiological information about the outbreaks (see Table S1: Supplementary material). According to the location of the Salmonella isolation, each clinical case was classified as enteric (intestine and feces), septicemic (internal organs), hepato-biliary invasive (liver and gallbladder), or nodal (lymph node).

\subsection{Salmonella Characterization}

One representative isolate of each clinical occurrence was phenotypically and genotypically characterized as follows:

\subsubsection{Serotyping}

The antigenic formula was determined by slide serum agglutination according to the White-Kauffmann-Le Minor scheme [26]. All Salmonella typhimurium isolates were submitted to a multiplex PCR protocol [27] to confirm a monophasic variant of S. typhimurium (antigenic formula: 4,[5],12:i:-) using previously described primers [28,29].

\subsubsection{Phenotypic Antimicrobial Resistance Profile}

Antimicrobial susceptibility testing was carried out using the disk diffusion method [30] against 14 antimicrobials (Oxoid, Hampshire, UK): ceftiofur (CEF, $30 \mu \mathrm{g}$ ), ciprofloxacin $(\mathrm{CIP}, 5 \mu \mathrm{g})$, doxycycline (DOX, $30 \mu \mathrm{g})$, enrofloxacin (ENR, $5 \mu \mathrm{g})$, streptomycin (STR, $10 \mu \mathrm{g})$; florfenicol (FFC, $30 \mu \mathrm{g}$ ), fosfomycin (FOS, $200 \mu \mathrm{g})$; gentamicin (GEN, $10 \mu \mathrm{g}$ ), lincomycinspectinomycin (LSC, $9 \mu \mathrm{g}$ and $100 \mu \mathrm{g}$ ), marbofloxacin (MAR, $5 \mu \mathrm{g}$ ), neomycin (NEO, $30 \mu \mathrm{g}$ ), norfloxacin (NOR, $10 \mu \mathrm{g}$ ), sulfamethoxazole-trimethoprim (SXT, $23.75 \mu \mathrm{g}$ and $1.25 \mu \mathrm{g})$, and tetracycline (TET, $30 \mu \mathrm{g}$ ). The results were interpreted according to EUCAST version 9.0 [31].

For colistin (colistin sulfate, Sigma-Aldrich, Y0000277), the minimal inhibitory concentration (MIC) was determined using a broth microdilution method. The results were interpreted using EUCAST version 9.0 [31,32]. The Escherichia coli ATCC 25922 strain was used as a control test. All strains were also screened for the presence of the mcr-1.1 gene by PCR [33].

\subsubsection{Pulsed-Field Gel Electrophoresis (PFGE)}

The PFGE method was carried out as described in the PulseNet protocol (www.cdc. gov / pulsenet/pdf/ecoli-shigella-salmonella-pfge-protocol-508c.pdf) (accessed on 21 April 2021), using XbaI (New England Biolabs, Beverly, MA, USA) as a restriction enzyme for $2 \mathrm{~h}$ at $37^{\circ} \mathrm{C}$. Whole cell DNA of S. braenderup H9812 served as a size marker. Macro restriction patterns (pulsotypes) were analyzed using the BioNumerics software, version 3.0 (Applied Maths, Sint-Martens-Latem, Belgium) with a position tolerance of 1.7\% [34]. The similarities were determined by the Dice coefficient, and pulsotypes were clustered by the unweighted pair group method using arithmetic averages (UPGMA). Isolates were considered to belong to the same pulsotype when the number and location of the bands were indistinguishable $(100 \%$ similarity).

\subsubsection{Whole Genome Sequencing (WGS)}

A subset of six $S$. choleraesuis strains belonging to the same PFGE pulsotype from septicemic outbreaks that occurred in 2011 and 2016, distributed among the largest pigproducing states (MG, GO, PR, RS, SC, SP) and having different antimicrobial resistance profiles, were submitted for WGS. The selected strains are marked with an " $X^{\prime}$ " in Figure S1 (Supplementary material). The genomic DNA was purified and quantified in triplicate with the Quant-iT dsDNA HS assay (Invitrogen, Carlsbad, CA, USA) in an Eppendorf AF2200 
plate reader (Eppendorf, Hamburg, Germany). Genomic DNA libraries were prepared using Nextera XT Library Prep Kit (Illumina, San Diego, CA, USA). DNA quantification and library preparation were carried out on a Hamilton Microlab STAR (Hamilton, Bonaduz, Switzerland) automated liquid handling system. Pooled libraries were quantified using the Kapa Biosystems Library Quantification Kit for Illumina on a Roche LightCycler 96 qPCR machine (Roche Molecular Systems, Pleasanton, CA, USA). Libraries were sequenced on the Illumina HiSeq (Illumina, San Diego, CA, USA) using a 250 bp paired-end protocol. Reads were adapter trimmed using the Trimmomatic 0.30 with a sliding window quality cutoff of Q15 [35]. De novo assembly was performed on samples using SPAdes version 3.7 [36], and contigs were annotated using Prokka 1.11 [37].

\subsubsection{WGS Analysis}

The serotyping was confirmed with SeqSero version 1.0 [38]. Multilocus sequence typing (ST) was performed with MLST 2.0 [39]. Antimicrobial resistance gene and chromosomal point mutations gene in the genome were determined using ResFinder 4.0 [40] with a selected threshold equal to $90 \%$ for minimum identification and selected minimum length to $60 \%$. For the identification of plasmids, annotated assemblies from this study were used to generate a pangenome with Roary [41] in comparison with a reference whole genome assembly of S. choleraesuis ATCC 10708, using the default settings. Following the pangenome analysis, gifrop (https:/ / github.com/Jtrachsel/gifrop, accessed on 12 April 2021) was used to identify genomic islands, or regions that were not part of the core genome (denoted "non-core"). For the purposes of this analysis, any gene that was not present in all genomes, including the reference genome, was considered to be a "non-core" gene. Genomic regions of interest, including plasmids, are consecutive strings of non-core genes. This software classifies these regions of interest by identifying antibiotic resistance and plasmid marker genes with ABRicate using the MEGARes 2.0 and PlasmidFinder databases, respectively [42,43]. All regions identified as non-core were compared with previously identified complete plasmids from an NCBI-based plasmid database [44] with BLAST [45]. In addition, RFPlasmid (https://github.com/aldertzomer/RFPlasmid, accessed on 12 April 2021) was used to predict whether a contig in each assembly was likely part of a plasmid [46].

Single nucleotide polymorphisms (SNPs) were determined using the pipeline CSI Phylogeny 1.4 package [47], available on the CGE site, using reference strain S. choleraesuis AE017220 and according to the following parameters: (1) minimum coverage of 10 , (2) minimum distance of 15 bp between each SNP, (3) minimum quality score for each SNP at 30, and (4) excluding all indels [15]. The SNPs from each genome were concatenated to a single alignment corresponding to the position of the reference genome and subjected to multiple alignments. The final phylogenetic SNP tree was computed via MEGAX using the maximum likelihood method [48].

\section{Results}

This study investigated 130 Salmonella isolates originating from pig salmonellosis outbreaks from 2011 to 2017 in 10 Brazilian states, distributed among 71 known municipalities (see Figure 1). 


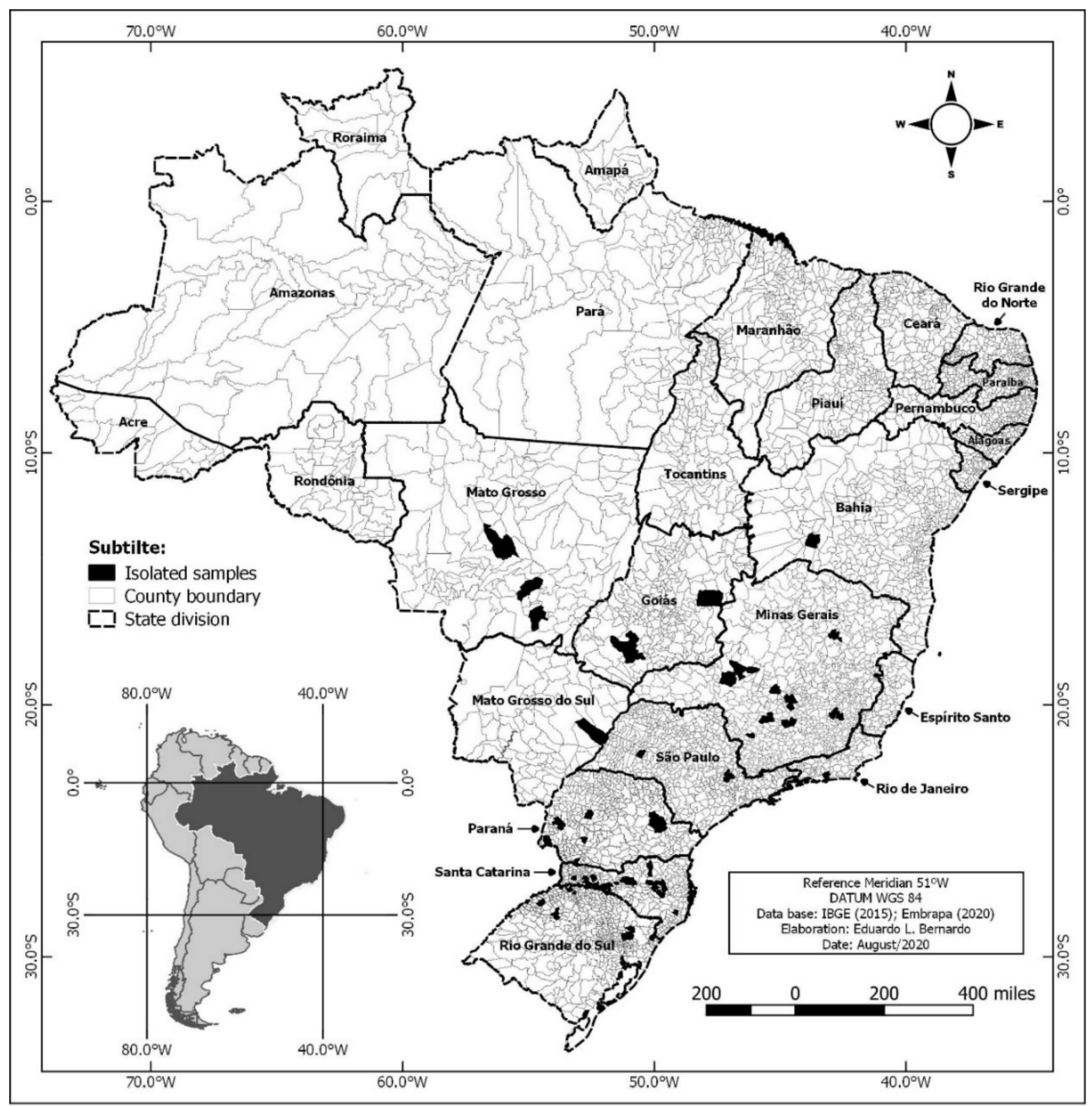

Figure 1. Geographic distribution of 130 Salmonella strains from pig salmonellosis outbreaks in 10 Brazilian states from 2011 to 2017.

\subsection{Serotyping}

Results from the serotyping method revealed that $42.31 \%(55 / 130)$ of the strains were a monophasic variant of $S$. typhimurium, followed by $35.40 \%(46 / 130)$ S. choleraesuis and $10.77 \%(14 / 130)$ S. typhimurium. Other serovars, such as S. Rissen (3/130), S. London $(2 / 130)$, and $S$. Panama $(2 / 130)$, were identified in lower numbers. Moreover, eight serovars were identified only once: S. Anatum, S. Bovismorbificans, S. Derby, S. Group D, S. Group E4 (O:19:-), S. Infantis, S. Newport and S. Oslo. Results from multiplex PCR confirmed the occurrence of the monophasic variant of $S$. typhimurium previously classified by the serotyping method.

Table 1 presents an overview of the outbreaks' characterization. Assessing the production phase of 114 outbreak cases showed that eight occurred during the suckling period, 53 occurred in the nursery, and 53 occurred in the growing/finishing phase, while 16 outbreaks did not document the farming phase. Out of 130 clinical cases, 50 were classified as enteric, 48 were septicemic, 17 were hepato-biliary invasive, and 13 were nodal or enteric nodal. 
Table 1. Distribution of 130 salmonellosis outbreaks by farming phase, clinical-pathological classification, and serovar.

\begin{tabular}{|c|c|c|c|c|c|}
\hline Farming Phase & $\mathbf{N}$ & Clinical-Pathological Classification & $\mathbf{N}$ & Serovars & $\mathbf{N}$ \\
\hline \multirow{6}{*}{ Suckling } & \multirow{6}{*}{8} & & & Newport & 1 \\
\hline & & Enteric & 4 & Rissen & 1 \\
\hline & & & & * Monophasic Typhimurium & 2 \\
\hline & & Hepato-biliary invasive & 1 & Choleraesuis & 1 \\
\hline & & Nodal & 1 & * Monophasic Typhimurium & 1 \\
\hline & & Septicemic & 2 & Choleraesuis & 2 \\
\hline \multirow{8}{*}{ Nursery } & \multirow{8}{*}{53} & Enteric & 20 & $\begin{array}{l}\text { Typhimurium } \\
\text { * Monophasic Typhimurium }\end{array}$ & $\begin{array}{c}4 \\
16\end{array}$ \\
\hline & & Hepato-biliary invasive & 4 & $\begin{array}{c}\text { Choleraesuis } \\
* \text { Monophasic Typhimurium }\end{array}$ & $\begin{array}{l}2 \\
2\end{array}$ \\
\hline & & \multirow{2}{*}{ Nodal } & \multirow{2}{*}{3} & Choleraesuis & 2 \\
\hline & & & & Panama & 1 \\
\hline & & \multirow{4}{*}{ Septicemic } & \multirow{4}{*}{26} & Anatum & 1 \\
\hline & & & & Choleraesuis & 19 \\
\hline & & & & Typhimurium & 1 \\
\hline & & & & * Monophasic Typhimurium & 5 \\
\hline \multirow{17}{*}{ Growing/Finishing } & \multirow{17}{*}{53} & \multirow{4}{*}{ Enteric } & \multirow{4}{*}{22} & Infantis & 1 \\
\hline & & & & Rissen & 1 \\
\hline & & & & Typhimurium & 5 \\
\hline & & & & * Monophasic Typhimurium & 15 \\
\hline & & \multirow{5}{*}{ Hepato-biliary invasive } & \multirow{5}{*}{11} & Choleraesuis & 2 \\
\hline & & & & London & 1 \\
\hline & & & & Oslo & 1 \\
\hline & & & & Typhimurium & 1 \\
\hline & & & & * Monophasic Typhimurium & 6 \\
\hline & & \multirow{5}{*}{ Nodal } & \multirow{5}{*}{8} & Choleraesuis & 2 \\
\hline & & & & Derby & 1 \\
\hline & & & & London & 1 \\
\hline & & & & Typhimurium & 2 \\
\hline & & & & ${ }^{*}$ Monophasic Typhimurium & 2 \\
\hline & & \multirow{3}{*}{ Septicemic } & \multirow{3}{*}{12} & Choleraesuis & 7 \\
\hline & & & & Grupo D & 1 \\
\hline & & & & * Monophasic Typhimurium & 4 \\
\hline \multirow{9}{*}{ No information } & \multirow{9}{*}{16} & \multirow{4}{*}{ Enteric } & \multirow{4}{*}{4} & Grupo E4 (O:19:-) & 1 \\
\hline & & & & Panama & 1 \\
\hline & & & & Typhimurium & 1 \\
\hline & & & & * Monophasic Typhimurium & 1 \\
\hline & & Hepato-biliary invasive & 1 & Rissen & 1 \\
\hline & & Nodal & 1 & Choleraesuis & 1 \\
\hline & & Septicemic & 8 & Choleraesuis & 8 \\
\hline & & \multirow[b]{2}{*}{ NI } & \multirow[b]{2}{*}{2} & Bovismorbificans & 1 \\
\hline & & & & * Monophasic Typhimurium & 1 \\
\hline
\end{tabular}

* Monophasic variant of S. typhimurium (4,[5],12:i:-).

Serovar Typhimurium (monophasic variant plus Typhimurium) were isolated from $88 \%(44 / 50)$ of the enteric cases, and serovar Choleraesuis was isolated from $75 \%(36 / 48)$ of the classical septicemic clinical cases. Notably, the monophasic variant of $S$. typhimurium presented nine strains related to septicemic cases. 


\subsection{Phenotypic Antimicrobial Resistance Profile}

Regarding the phenotypic antimicrobial resistance profile, out of 130 isolates, only one was fully susceptible to all tested antimicrobials. The majority, 113 isolates $(86.92 \%)$, showed resistance to three or more antimicrobial classes and were classified as multidrug resistant (MDR) [49]. The highest frequency of resistant isolates was found against tetracycline $(90 \%)$, followed by florfenicol $(77.69 \%)$, doxycycline $(76.92 \%)$, gentamicin $(73.84 \%)$, colistin $(63.07 \%)$, and streptomycin $(62.30 \%)$. In contrast, $96.92 \%$ of the strains were susceptible to fosfomycin, followed by lincomycin-spectinomycin at $81.54 \%$, ceftiofur at $80.76 \%$, and norfloxacin at $75.38 \%$ (Figure 2).

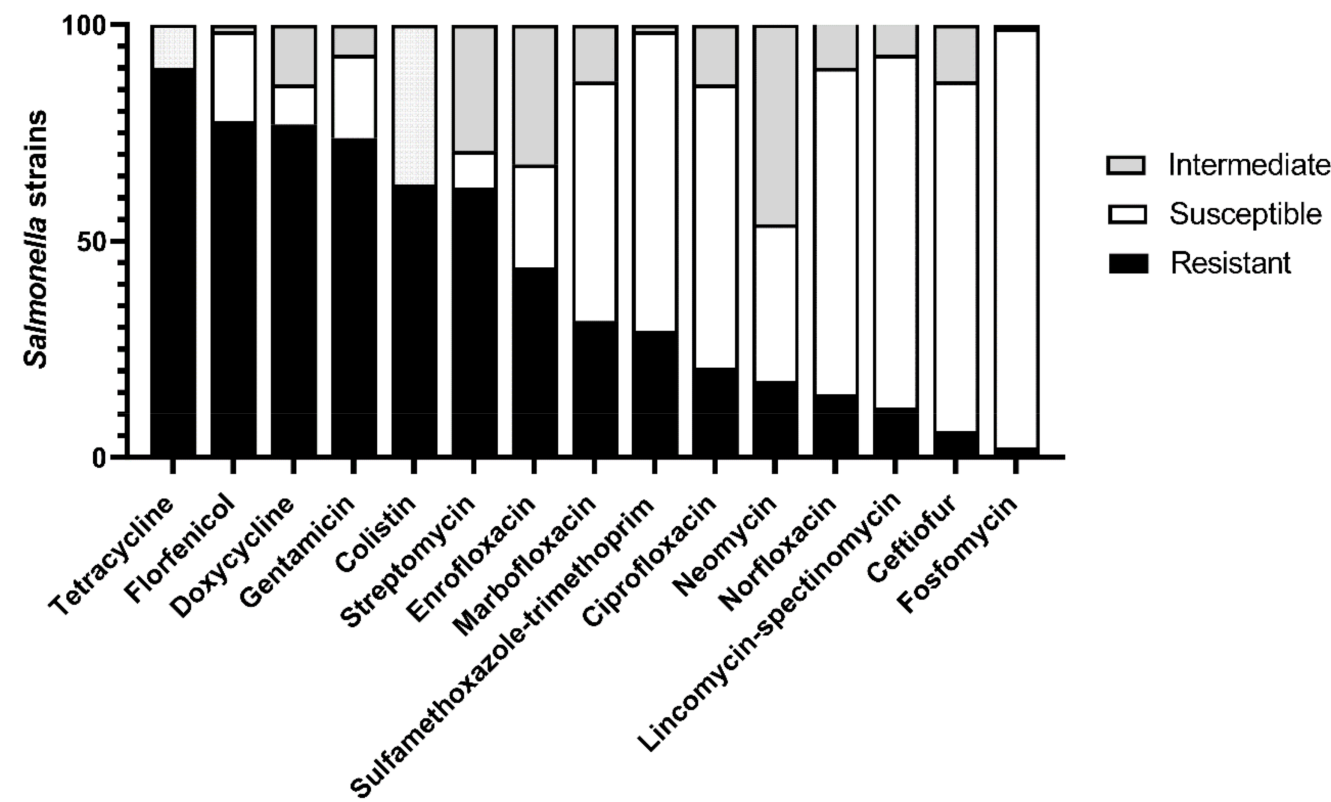

Figure 2. Percentage of in vitro antimicrobial resistance of 130 Salmonella strains from pig salmonellosis against 14 antimicrobials by disk diffusion method. Resistance to colistin was determined by minimal inhibitory concentration (MIC) using a broth microdilution method. Results for both methods were interpreted according to EUCAST version 9.0.

A total of 14 (10.77\%) Salmonella isolates distributed in six Brazilian states (DF, MG, PR, RS, SC, and SP) from 2013 to 2017 were positive for $m c r-1.1$. A total of 13 strains were identified as a monophasic variant of $S$. typhimurium, and one strain was serovar Choleraesuis. All the positive $m c r-1.1$ gene strains exhibited MIC values of $8 \mu \mathrm{g} / \mathrm{mL}$ for colistin and were classified as resistant.

\subsection{Pulsed-Field Gel Electrophoresis (PFGE)}

The macrorestriction analysis resulted in a total of 38 pulsotypes and 17 clusters (see Figure S1: Supplementary material). One major Choleraesuis clonal group with 42 isolates, called pulsotype $\mathrm{C} 2$, was widely distributed in the pig production area encompassing six states: GO, MG, PR, RS, SC, and SP (Figure 3). Among these, 11 isolates belonged to outbreaks from 2011, while four isolates were obtained in 2012, two in 2014, eight in 2015, 13 in 2016, and four in 2017. Furthermore, a total of 14 isolates that belonged to the pulsotype $\mathrm{C} 2$ showed the same antimicrobial resistance profile [DOX, FFC, GEN, STR, TET], and eight more strains contained the same basic profile with other additional antibiotics (Figure 3). Conversely, the serovar monophasic variant of $S$. typhimurium presented eight different clusters with a broad diversity in the phenotypic antimicrobial resistance profile. The largest one, pulsotype SM-5, encompassed 19 isolates with only three exhibiting the same antimicrobial resistance profile [CIP, COL, DOX, ENR, FFC, GEN, MAR, NOR, STR, SXT, TET] (see Figure S2: Supplementary material). For S. typhimurium, three small clusters 
were obtained, in which pulsotype T1 with a total of five isolates from SC and RS comprised the greatest portion.

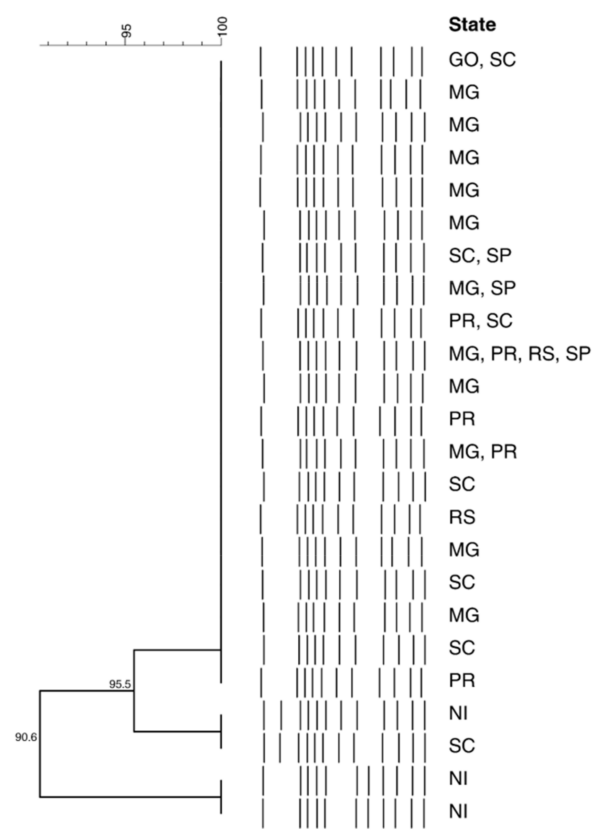

Antimicrobial Resistance
COL, DOX, ENR, FOS, GEN, MAR, STR, TET
COL, DOX, FFC, GEN, LSC, STR, TET
DOX, ENR, FFC, GEN, MAR, STR, TET
DOX, ENR, FFC, GEN, NEO, STR, TET
DOX, FFX, GEN, MAR, NEO, STR, TET
COL, DOX, ENR, FFC, STR, TET
COL, DOX, FFX, GEN, STR, TET
DOX, ENR, FFC, GEN, STR, TET
COL, DOX, FFC, GEN, TET
DOX, FFC, GEN, STR, TET
COL, DOX, FFC, TET
COL, FFC, STR, TET
DOX, FFC, GEN, TET
DOX, GEN, STR, TET
ENR, FFC, GEN, STR
FFC, GEN, STR, TET
COL, DOX, TET
DOX, FFC, TET
DOX, STR, TET
TET
DOX, ENR, FFC, GEN, STR, TET
DOX, NEO
COL, DOX, ENR, FFC, GEN, STR, TET
ENR, NEO

Figure 3. Salmonella Choleraesuis isolates segregated by pulsotype (PFGE technique) and antimicrobial resistance profile. The outbreak location by state and the number of isolates are indicated for each pattern. $N=$ number of isolates.

\subsection{Whole Genome Sequencing Analysis}

On the basis of the WGS data, all tested isolates were confirmed as being S. choleraesuis (7: c: 1, 5) and found to be the same sequence type (ST-145). The maximum likelihood SNP-based tree indicated difference of 11 to 47 SNPs (Figure 4).

All six isolates showed the common antimicrobial resistance gene for aminoglycoside (aac(3)-IV, aac( $\left.6^{\prime}\right)$-Iaa, aph(4)-Ia, aph(3")-Ib, aph(6)-Id), beta-lactam (blaTEM-1A), sulphonamide (sul2), and tetracycline $(\operatorname{tet}(B)$, tet $(D))$ as well as common chromosomal point mutations for parC (mutation: p.T57S) and gryA (mutation: p.S83Y). Both gene mutations conferred resistance to quinolone and fluoroquinolone. Four strains from PR, RS, SC, and SP states showed an acquired antimicrobial resistance gene for phenicol $(f l o R)$ and one strain (SC state) for colistin (mcr-1.1) (Figure 4).

Plasmid replicon-associated genes were detected in all isolates (Figure 4). All AMR carrying regions identified as "non-core" in the pangenome occupied the entirety of the contig they were identified on, meaning we found no evidence that these "non-core" regions with antimicrobial resistance genes were integrated into the chromosome. Additionally, the tool RFPlasmid, a random forest classifier, classified all contigs carrying these AMR genes of interest as "plasmid" with high confidence, and these contigs all had high identity blast hits to known complete plasmids. However, these plasmids were likely broken across several contigs in the assemblies. In all but one of the assemblies, only one contig contained plasmid marker genes. In these assemblies, the single contigs containing the plasmid marker genes had multiple marker genes: RepA_1_pKPC-CAV1321, IncHI2_1, and IncHI2A_1. Only one strain from SC state showed the possibility of two distinct plasmids, the second having an IncX4_1 plasmid marker gene. This strain was resistant to colistin and had this IncX4 plasmid carrying the mcr-1.1 gene, which is the mcr-1.1 gene that was located on the same contig with the IncX4 plasmid marker gene. Because of the fragmented nature of these assemblies, uncertainty remains regarding the precise nature of these AMR carrying elements. Even though, all evidence suggests the antimicrobial genes detected in the genomes were likely present on plasmids. 


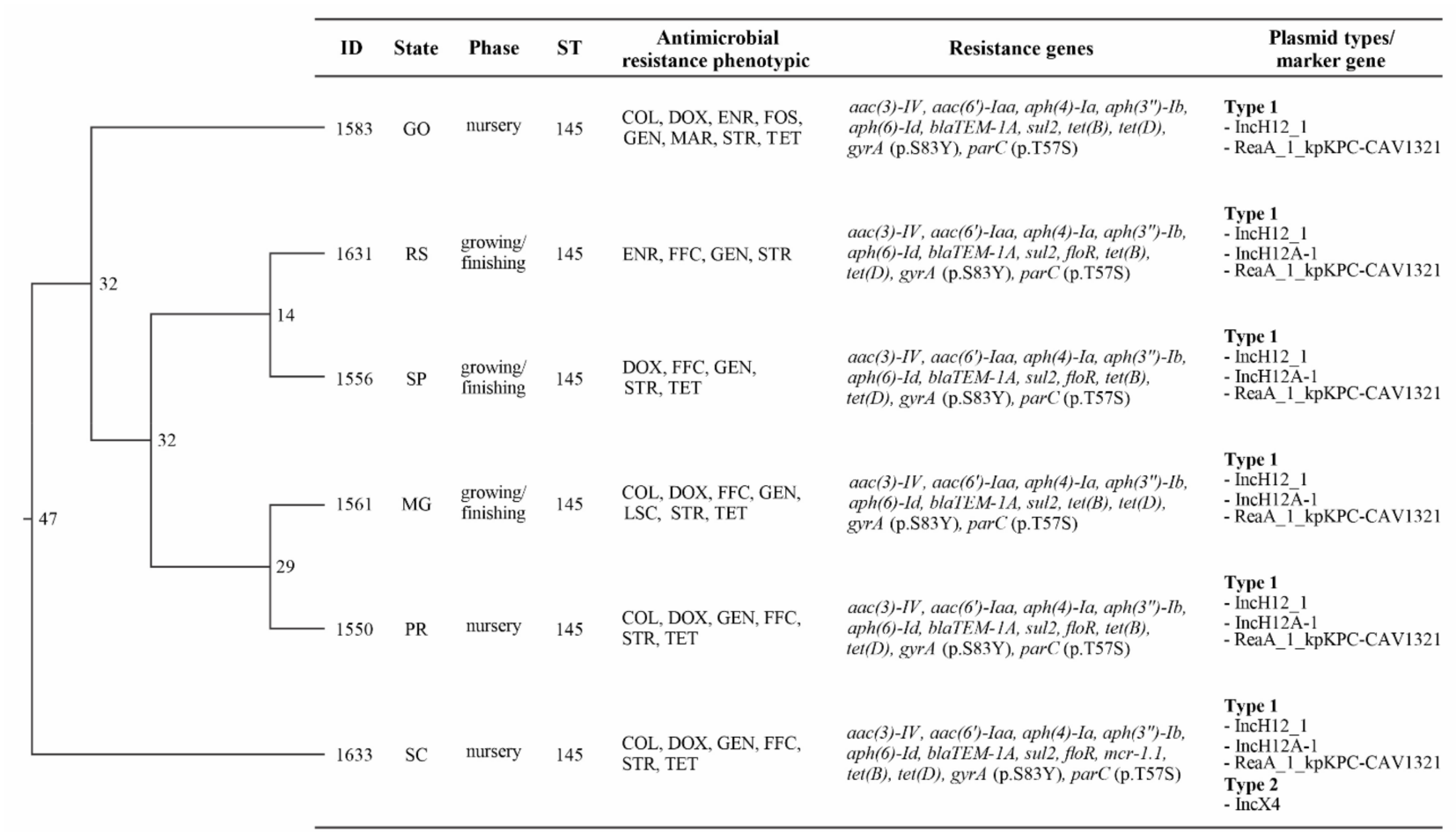

Figure 4. SNP tree together with results of the antimicrobial susceptibility tests, presence of antimicrobial resistance genes, and plasmids for the six sequenced isolates of Salmonella Choleraesuis from Brazil. SNP differences between branches are indicated with numbers in the dendrogram. COL, colistin; DOX, doxycycline; ENR, enrofloxacin; FOS, fosfomycin; FFC, florfenicol; GEN, gentamicin; LSC, lincomycin-spectinomycin; MAR, marbofloxacin; STR, streptomycin, TET, tetracycline; $\mathrm{ST}$, sequence type.

\section{Discussion}

The present study characterized 130 outbreaks of salmonellosis around Brazil, demonstrating similar occurrences in the nursery (53) and growing/finishing phases (53), while the disease occasionally occurred in suckling piglets. Among all reported outbreaks, 50 were well defined as enteric and 48 as septicemic, while 17 and 13 cases were characterized as hepato-biliary invasive and nodal, respectively. These last two definitions may belong to enteric or septicemic diseases; however, the available information did not allow this classification. The emergence and amplification of the illness may be related to factors such as the introduction of carrier animals, neglected biosafety, contaminated feed, failure of protocol, or inadequate cleaning and disinfection [4]. Wild boars have been described as Salmonella and antimicrobial resistance reservoirs [16-19], and could be a vector if biosafety protocols are not followed. Although the disease is uncommon in an early stage due to the transfer of maternal immunoglobulin, it was observed in atypical cases of salmonellosis in the suckling period (6.15\%) with both septicemic and enteric clinical-pathological presentations.

As expected, almost all of the $S$. choleraesuis isolates were from septicemic clinical cases based on the isolation site, mainly from the lungs (30/46). As a host-adapted pathogen, the S. choleraesuis infection typically causes severe systemic disease with lesions in a variety of organs. Regarding the enteric cases, the monophasic variant of S. typhimurium was the most common serovar associated with clinical salmonellosis outbreaks that spread in several states by $68 \%(34 / 50)$. Similarly, it was demonstrated by an increase in the prevalence of a monophasic variant of $S$. typhimurium recovered from swine samples comparing 2006 to 2015 [50]. According to other studies, the high frequency of clinical cases caused by the monophasic variant of S. typhimurium and S. typhimurium is due to the broad host range of these serovars [4]. Interestingly, some septicemic cases $(9 / 48)$ linked to the monophasic variant of $S$. typhimurium were observed, consistent with a previous 
study that demonstrated the ability of this serovar to cause transient clinical disease in pigs, associated with high body temperature, diarrhea, and changes in the gastrointestinal microbiota [51]. This Salmonella variant has emerged as an MDR strain in recent years with global dissemination and strong correlation to pig and pork products [6,52].

Typing 47 out of 55 monophasic variants of $S$. typhimurium strains by PFGE resulted in eight pulsotypes, the largest clonal group encompassing 19 isolates distributed in 18 municipalities (see Figure S2: Supplementary Material). Genetic screening of the monophasic variant of $S$. typhimurium strains pointed out resistant genes to copper, silver, and mercury, which might favor the serovar's capability to survive in a farming environment and enhance the bacteria's dissemination [53].

The antimicrobial resistance profile of Salmonella isolates recovered from clinical outbreaks may provide a powerful framework for veterinarians to apply an efficient therapeutic antibiotic treatment to reduce the misuse of such drugs in pig herds. The high percentage of resistance to tetracycline derivatives (tetracycline and doxycycline) and florfenicol corroborate previous reports $[22,54]$. According to the resistance profile, most of the strains were classified as MDR. On a related note, historical antimicrobial use in animal production has been favoring the incidence of MDR strains $[55,56]$.

Twenty-one isolates (16.15\%) demonstrated phenotypic resistance to 10 or more antimicrobials used, out of a total of 15 antimicrobials tested, revealing isolates that were resistant to various drugs used in pig farming. However, although ceftiofur is widely used in the swine clinic, mainly in cases of enteritis, few isolates were resistant to this antibiotic. In contrast, we found a significant amount of resistance to another well-used antibiotic like florfenicol. Marbofloxacin is used for genitourinary, respiratory, enteric, and systemic infections of pigs. Unfortunately, resistance persists in specific field situations where a molecule, such as tetracycline, is not used for many years, even more than a decade. These results may be explained by cross and co-resistance phenomes. In the first case, the microorganism shares the same resistance mechanism against more than one antimicrobial: the classic example is the gene $f l o R$, which confers resistance to florfenicol and chloramphenicol [57]. Co-resistance is driven by a specific antimicrobial selection of a microorganism that harbors a plasmid encompassing several resistance genes. In this case, the effect of one antimicrobial is enough to select the entire plasmid, which persists in the microbial community.

Nowadays, antimicrobial resistance is one focus of the One Health discussion and represents a critical issue to human and animal health. From this perspective, the common use of colistin in swine production [58] may have favored the emergence of resistant $(m c r)$ genes carried in transferable plasmids [59]. Even though $63.7 \%$ of isolates were resistant in phenotypic characterization only $10.77 \%$ showed the $m c r-1.1$ gene. In Brazil, colistin was widely used in pig production until it was banned as a feed additive in 2016. Currently, its administration is allowed only for therapeutic use [60].

One large cluster with $S$. choleraesuis strains showing an identical pulsotype was widely spread in several states over the years. The majority shared a resistance profile, strongly indicating that the strains had a common origin, belonging to the same clonal group. Although PFGE has been considered the gold standard molecular epidemiological tool, whole genome sequencing (WGS) has emerged as an alternative tool offering high discriminatory power. To support the same origin hypothesis of the aforementioned cluster, the results from WGS of the six S. choleraesuis strains, representing different states, have confirmed the relatedness of these strains. Although their phenotypic antimicrobial resistance profile was not the same, this result is likely related to the different antimicrobial protocols used around the country. While only one isolate had phenotypic resistance to marbofloxacin and two isolates to enrofloxacin, all resistance genes to fluoroquinolones were found ( $g y r A$ ). To detect ciprofloxacin resistance in the Salmonella genus, it is recommended to use the pefloxacin $5 \mu \mathrm{g}$ disk, since the ciprofloxacin disk does not reliably detect the low-level of resistance [30]. This fact can explain the contradictory ciprofloxacin phenotypic results in isolates that harbor the gyrA resistance gene that were classified as susceptible. For flor- 
fenicol, only one isolate showed phenotypic resistance to this drug without finding the floR or other florfenicol resistance genes, like clm [61]. Most of the florfenicol resistance genes are located in the mobile plasmids and the transposons. However, in this case, it was not possible to discover what the resistance mechanism was in this isolate, perhaps due to gene loss, fewer reads of the sequence from WGS, or another efflux pump. This mechanism also explains the presence of the fosfomycin resistance phenotype but without the associated chromosomal gene (fos $A$ ) [62]. Although the presence of the fos A7 gene in Salmonella was reported in 2017 [63], it has not yet been reported in the Choleraesuis serovar.

Regarding colistin resistance, only one isolate carried the $m c r-1.1$ gene, predicted to confer resistance to this antibiotic. Even so, a resistance phenotype was found in another isolate, possibly related to an efflux pump, because there were no other resistance genes to colistin in this isolate [64]. Aminoglycoside genes, responsible for streptomycin phenotype resistance (aph ( $\left.3^{\prime \prime}\right)-I b$, aph(6)-Id) and gentamicin phenotype resistance (aac(3)-IV) were detected in all sequenced strains. Concerning tetracycline resistance, only one isolate did not show phenotype resistance, but all isolates carry tetracycline resistance genes. No isolate showed phenotypic resistance to sulfonamide antimicrobial when tested for sulfamethoxazole-trimethoprim; however, the gene sul2 was present in the six strains. Comparing all the isolates, we noticed a common genotype pattern among them, with the same resistance markers for aminoglycosides, fluoroquinolone, tetracycline, beta-lactam, sulfonamide, and tetracycline classes, supporting the idea that these genes are present in a mobile element, such as a plasmid, persisting among those isolated by time and region.

In all sequenced strains, the plasmid marker gene IncHI2 was found. IncHI2 has previously been identified as the major plasmid lineage contributing to the dissemination of antibiotic resistance in Salmonella [65]. Due to the fragmented nature of the draft genome assemblies, it is not possible to confirm the exact genetic compartment (plasmid vs. chromosome) of resistance genes in these strains. However, multiple pieces of evidence suggest these AMR genes are plasmid-associated. Firstly, all contigs that carry AMR genes were predicted to be plasmid-associated by RFPlasmid. Secondly, according to the pangenome analysis, we found no evidence that these AMR carrying "non-core" regions were integrated into the chromosome that is, no chromosomal genes were detected on these putative plasmid contigs. Thirdly, all AMR carrying "non-core" regions had high identity blast hits to known plasmids from the PLSDB database. However, the mcr-1.1 gene was located on the same contig as the IncX4 plasmid marker gene, unambiguously linking this colistin resistance gene to an IncX4-type plasmid. In Brazil, the same gene has already been described in plasmid Inc $X 4$ in an isolate from $S$. choleraesuis from human bloodstream infections [66]. Nevertheless, our work is the first to report a $m c r-1.1$ carrying IncX4 plasmid from a swine salmonellosis clinic in Brazil. The putative plasmids detected in most of these isolates had combinations of marker genes, IncHI2_1A, IncHI2A-1, and RepA_1_pKPCCAV1321, that have never been described before in Salmonella, according to the last version of the PlasmidFinder database (03 20 2021). Plasmids with these combinations of marker genes have been previously detected in Enterobacter cloacae [67], Citrobacter freundii, and Klebsiella pneumoniae [68], which were always carrying beta-lactam resistance. In our sequence strains, all showed the blaTEM-1A gene. These results suggest the transfer of plasmids play a role in disseminating AMR genes of concern in swine in Brazil and it will be necessary to employ long-read sequencing technology to help resolve these difficult to assemble, but important genetic elements.

All sequenced strains showed the same sequence type (ST-145) [39]. This ST is commonly related to strains of $S$. choleraesuis var. Kunzendorf [17]. In the MLST database, 34 isolates are deposited with the same ST, and only two have not been confirmed as belonging to the serovar Choleraesuis. Regarding differences in the SNPs, there is no clear consensus about how many different SNPs can be considered clones or not clones [69]. The analysis used considered the SNPs located in genes observed in all analyzed genomes; thus, information from the accessory genome was discarded [70]. Of the six S. choleraesuis sequenced in this study, 11 to 47 different SNPs were discovered, which should be considered 
a low number. Our other analyses involving MLST, PFGE, and antimicrobial resistance profile, also suggest the strains are closely related. The mutation rate of the $S$. choleraesuis was 1.02 SNPs/genome/year [17], data that must be considered when comparing isolates from different years. In a previous study, S. choleraesuis isolates that presented identical PFGE profile with a difference of 23 or 67 SNPs were considered epidemiologically related [15]. In contrast, $S$. typhimurium strains have exhibited more genetic differences and phenotypic heterogeneity over the years. This phenomenon may be attributed to the ubiquitous features of this serovar in Brazilian pig farms [71] and to the diverse antimicrobial exposures that the bacteria undergo in different animal husbandry environments [72].

\section{Conclusions}

Clinical salmonellosis is endemic in the most important pig-producing states in Brazil. The most prevalent serovars are a monophasic variant of S. typhimurium, S. choleraesuis, and S. typhimurium and have displayed a high rate of antimicrobial multi-resistance. Subset strains showed a common genotypic profile, with gene markers for aminoglycosides, fluoroquinolone, tetracycline, beta-lactam, sulfonamide, and tetracycline classes. However, differences were seen in phenotypic resistance, probably because of variations in the antibiotics protocol used. The $S$. choleraesuis strains from different regions of the country were closely related and likely had a common origin. Regarding S. typhimurium, several small groups were widely distributed, and the monophasic variant of S. typhimurium appears to be an emerging serotype causing clinical disease in swine.

Supplementary Materials: The following are available online at https: / www.mdpi.com/article / 10.3390/microorganisms9050947/s1, Table S1: epidemiological information database, Figure S1: Dendrogram of 130 Salmonella isolates according to pulsotype, outbreak location, serovar antimicrobial resistance profile, Figure S2: Dendrogram of monophasic variant of S. typhimurium isolates according to pulsotype, outbreak location, and antimicrobial resistance profile.

Author Contributions: Conceptualization, M.M., R.M.C.G. and J.D.K.; methodology, M.M., C.P., R.R., J.T., S.S.K., A.T.R., J.A.L. and C.R.; formal analysis, M.M., C.P., R.R. and J.T.; writing-original draft preparation, M.M., C.P., R.R., J.T., S.S.K., A.T.R., J.A.L. and C.R.; writing-review and editing, M.M., R.M.C.G. and J.D.K.; supervision, J.D.K.; project administration, J.D.K.; funding acquisition, J.D.K. All authors have read and agreed to the published version of the manuscript.

Funding: M. Meneguzzi was supported by a scholarship from the National Council for Scientific and Technological Development (CNPq), C. Pissetti was supported by the Coordination of Improvement of Higher Education Personnel-Brazil (CAPES)-Financing Code 001 (PNPD scholarship), and R.M.C. Guedes has a research fellowship from CNPq.

Informed Consent Statement: Not applicable.

Data Availability Statement: Salmonella Choleraesuis strains sequences were submitted to GenBank with the following accession numbers: SAMN17052566 (JAEMXF000000000); SAMN17052567 (JAEMXE000000000); SAMN17052568 (JAEMXD000000000); SAMN17052569 (JAEMXC000000000); SAMN17052570 (JAEMXB000000000); SAMN17052571 (JAEMXA000000000).

Acknowledgments: The authors would like to thank Luiza Leticia Biesus and the Cedisa group for technical support, and Cedisa, Mercolab and Ipeve laboratories for Salmonella isolates. Genome sequencing, provided by MicrobesNG, was supported by the BBSRC (grant number BB/L024209/1).

Conflicts of Interest: The authors declare no conflict of interest.

\section{References}

1. Gavin, C.; Simons, R.; Berriman, A.; Moorhouse, D.; Snary, E.; Smith, R.; Hill, A. A cost-benefit assessment of Salmonella-control strategies in pigs reared in the United Kingdom. Prev. Veter Med. 2018, 160, 54-62. [CrossRef]

2. Issenhuth-Jeanjean, S.; Roggentin, P.; Mikoleit, M.; Guibourdenche, M.; de Pinna, E.; Nair, S.; Fields, P.I.; Weill, F.-X. Supplement 2008-2010 (no. 48) to the White-Kauffmann-Le Minor scheme. Res. Microbiol. 2014, 165, 526-530. [CrossRef] [PubMed]

3. World Health Organization. WHO Estimates of the Global Burden of Foodborne Diseases: Foodborne Disease Burden Epidemiology Reference Group 2007-2015. Available online: https://apps.who.int/iris/handle/10665/199350 (accessed on 15 April 2021). 
4. Griffith, R.W.; Carlson, S.A.; Krull, A.C. Salmonellosis. In Diseases of Swine; Zimmerman, J.J., Karriker, L.A., Ramirez, A., Schwartz, K.J., Stevenson, G.W., Zhang, J., Eds.; Wiley Blackwell: Hoboken, NJ, USA, 2019; pp. 912-925.

5. Hurd, H.S.; Mckean, J.D.; Griffith, R.W.; Wesley, I.V.; Rostagno, M.H. Salmonella enterica Infections in Market Swine with and without Transport and Holding. Appl. Environ. Microbiol. 2002, 68, 2376-2381. [CrossRef]

6. Argüello, H.; Sørensen, G.; Carvajal, A.; Baggesen, D.L.; Rubio, P.; Pedersen, K. Characterization of the EmergingSalmonella4,[5],12:i:in Danish Animal Production. Foodborne Pathog. Dis. 2014, 11, 366-372. [CrossRef]

7. Barco, L.; Barrucci, F.; Cortini, E.; Ramon, E.; Olsen, J.E.; Luzzi, I.; Lettini, A.A.; Ricci, A. Ascertaining the relationship between Salmonella typhimurium and Salmonella 4,[5],12:i:- by MLVA and inferring the sources of human salmonellosis due to the two serovars in Italy. Front. Microbiol. 2015, 6, 301. [CrossRef]

8. Possebon, F.S.; Casas, M.R.T.; Nero, L.A.; Yamatogi, R.S.; Araújo, J.P., Jr.; Pinto, J.P.D.A.N. Prevalence, antibiotic resistance, PFGE and MLST characterization of Salmonella in swine mesenteric lymph nodes. Prev. Veter Med. 2020, 179, 105024. [CrossRef]

9. Rau, R.B.; De Lima-Morales, D.; Wink, P.L.; Ribeiro, A.R.; Barth, A.L. Salmonella enterica mcr-1 Positive from Food in Brazil: Detection and Characterization. Foodborne Pathog. Dis. 2020, 17, 202-208. [CrossRef]

10. Arruda, B.L.; Burrough, E.R.; Schwartz, K.J. Salmonella enterica I 4,[5],12:i:- Associated with Lesions Typical of Swine Enteric Salmonellosis. Emerg. Infect. Dis. 2019, 25, 1377-1379. [CrossRef]

11. Naberhaus, S.A.; Krull, A.C.; Arruda, B.L.; Arruda, P.; Sahin, O.; Schwartz, K.J.; Burrough, E.R.; Magstadt, D.R.; Ferreyra, F.M.; Gatto, I.R.H.; et al. Pathogenicity and Competitive Fitness of Salmonella enterica Serovar 4,[5],12:i:- Compared to Salmonella typhimurium and Salmonella Derby in Swine. Front. Veter Sci. 2020, 6, 502. [CrossRef] [PubMed]

12. Chiu, C.-H.; Su, L.-H.; Chu, C. Salmonella enterica Serotype Choleraesuis: Epidemiology, Pathogenesis, Clinical Disease, and Treatment. Clin. Microbiol. Rev. 2004, 17, 311-322. [CrossRef] [PubMed]

13. Stevens, M.P.; Gray, J.T. Salmonella infections in pigs. In Salmonella in Domestic Animals; Barrow, P.A., Methner, U., Eds.; CABI International: Wallingford, UK, 2013; pp. 263-294.

14. Asai, T.; Namimatsu, T.; Osumi, T.; Kojima, A.; Harada, K.; Aoki, H.; Sameshima, T.; Takahashi, T. Molecular typing and antimicrobial resistance of Salmonella enterica subspecies enterica serovar Choleraesuis isolates from diseased pigs in Japan. Comp. Immunol. Microbiol. Infect. Dis. 2010, 33, 109-119. [CrossRef]

15. Pedersen, K.; Sørensen, G.; Löfström, C.; Leekitcharoenphon, P.; Nielsen, B.; Wingstrand, A.; Aarestrup, F.M.; Hendriksen, R.S.; Baggesen, D.L. Reappearance of Salmonella serovar Choleraesuis var. Kunzendorf in Danish pig herds. Veter Microbiol. 2015, 176, 282-291. [CrossRef]

16. Methner, U.; Heller, M.; Bocklisch, H. Salmonella enterica subspecies enterica serovar Choleraesuis in a wild boar population in Germany. Eur. J. Wildl. Res. 2009, 56, 493-502. [CrossRef]

17. Leekitcharoenphon, P.; Sørensen, G.; Löfström, C.; Battisti, A.; Szabo, I.; Wasyl, D.; Slowey, R.; Zhao, S.; Brisabois, A.; Kornschober, C.; et al. Cross-Border Transmission of Salmonella choleraesuis var. Kunzendorf in European Pigs and Wild Boar: Infection, Genetics, and Evolution. Front. Microbiol. 2019, 10, 179. [CrossRef]

18. Longo, A.; LoSasso, C.; Vitulano, F.; Mastrorilli, E.; Turchetto, S.; Petrin, S.; Mantovani, C.; Pozza, M.C.D.; Ramon, E.; Conedera, G.; et al. Insight into an outbreak of Salmonella Choleraesuis var. Kunzendorf in wild boars. Veter Microbiol. 2019, $238,108423$. [CrossRef]

19. Gil Molino, M.; Pérez, D.R.; Blanco, P.G.; Llario, P.F.; Molina, A.Q.; Sánchez, A.G.; Gerveno, J.M.C.; Gordo, L.G.; Cano, F.E.M.; Martínez, R.P.; et al. Outbreaks of antimicrobial resistant Salmonella Choleraesuis in wild boars piglets from central-western Spain. Transbound. Emerg. Dis. 2019, 66, 225-233. [CrossRef]

20. World Health Organization. Antimicrobial Resistance. Available online: www.who.int/news-room/fact-sheets/detail/ antimicrobial-resistance (accessed on 15 April 2021).

21. Associação Brasileira de Proteína Animal (ABPA). Annual Reporter; ABPA: São Paulo, Brazil, 2020; 160p.

22. Vannucci, F.A.; Oliveira, G.; Henriques, M.R.; Reis, K.C.P.; Bouillet, L.E.M.; Guimaraes, W.V.; Santos, D.L.; Santos, L.F.; Santos, J.S. Retrospective Study and Antimicrobial Susceptibilities of $S$ enterica Serovar Choleraesuis Isolated from Swine Salmonellosis Outbreaks during 2013 in Brazil. In Proceedings of the 23rd International Pig Veterinary Society (IPVS) Congress, Cancun, Mexico, 8-11 June 2014; Volume II, p. 269.

23. Santos, L.D.; Teixeira, R.; Santos, D.; Guimaraes, W.; Santos, J.L. Comparative Study of the Occurrence of S. enterica Serovar Choleraesuis Isolated from Swine Salmonellosis Outbreaks during 2013 to 2015 in Brazil. In Proceedings of the 24th International Pig Veterinary Society (IPVS) Congress, Dublin, Ireland, 7-10 June 2016; p. 276.

24. Olsen, J.; Brown, D.; Skov, M.; Christensen, J. Bacterial typing methods suitable for epidemiological analysis. applications in investigations of salmonellosis among livestock. Veter Q. 1993, 15, 125-135. [CrossRef] [PubMed]

25. Zhao, S.; McDermott, P.; White, D.; Qaiyumi, S.; Friedman, S.; Abbott, J.; Glenn, A.; Ayers, S.; Post, K.; Fales, W. Characterization of multidrug resistant Salmonella recovered from diseased animals. Veter Microbiol. 2007, 123, 122-132. [CrossRef]

26. Grimont, P.A.D.; Weil, F.X. Antigenic Formulae of the Salmonella Serovars, 9th ed.; WHO Collaborating Centre for Reference and Research on Salmonella: Paris, France, 2007.

27. Tennant, S.M.; Diallo, S.; Levy, H.; Livio, S.; Sow, S.O.; Tapia, M.; Fields, P.I.; Mikoleit, M.; Tamboura, B.; Kotloff, K.L.; et al. Identification by PCR of Non-typhoidal Salmonella enterica Serovars Associated with Invasive Infections among Febrile Patients in Mali. PLoS Negl. Trop. Dis. 2010, 4, e621. [CrossRef] [PubMed] 
28. Vanegas, R.A.; Joys, T.M. Molecular analyses of the phase-2 antigen complex 1,2,. of Salmonella spp. J. Bacteriol. 1995, 177, 3863-3864. [CrossRef]

29. Echeita, M.A.; Herrera, S.; Usera, M.A. Atypical, fljB-Negative Salmonella enterica subsp. enterica Strain of Serovar 4,5,12:i: Appears To Be a Monophasic Variant of Serovar Typhimurium. J. Clin. Microbiol. 2001, 39, 2981-2983. [CrossRef]

30. EUCAST. The European Committee on Antimicrobial Susceptibility Testing, 2019a Antimicrobial Susceptibility Testing EUCAST Disk Diffusion Method, 1-21. Available online: www.eucast.org (accessed on 10 December 2020).

31. EUCAST. The European Committee on Antimicrobial Susceptibility Testing, 2019b Breakpoint Tables for Interpretation of MICs and Zone Diameters Version 9.0. Available online: www.eucast.org (accessed on 10 December 2020).

32. EUCAST. The European Committee on Antimicrobial Susceptibility Testing, Recommendations for MIC Determination of Colistin (Polymyxin E) as Recommended by the Joint CLSI-EUCAST Polymyxin Breakpoints Working Group. Available online: www.eucast.org (accessed on 10 December 2020).

33. Liu, Y.-Y.; Wang, Y.; Walsh, T.R.; Yi, L.-X.; Zhang, R.; Spencer, J.; Doi, Y.; Tian, G.; Dong, B.; Huang, X.; et al. Emergence of plasmid-mediated colistin resistance mechanism MCR-1 in animals and human beings in China: A microbiological and molecular biological study. Lancet Infect. Dis. 2016, 16, 161-168. [CrossRef]

34. Carrico, J.A.; Pinto, F.R.; Simas, C.; Nunes, S.; Sousa, N.G.; Frazão, N.; De Lencastre, H.; Almeida, J.S. Assessment of Band-Based Similarity Coefficients for Automatic Type and Subtype Classification of Microbial Isolates Analyzed by Pulsed-Field Gel Electrophoresis. J. Clin. Microbiol. 2005, 43, 5483-5490. [CrossRef] [PubMed]

35. Bolger, A.M.; Lohse, M.; Usadel, B. Trimmomatic: A flexible trimmer for Illumina sequence data. Bioinformatics 2014, 30, 2114-2120. [CrossRef] [PubMed]

36. Bankevich, A.; Nurk, S.; Antipov, D.; Gurevich, A.A.; Dvorkin, M.; Kulikov, A.S.; Lesin, V.M.; Nikolenko, S.I.; Pham, S.; Prjibelski, A.D.; et al. SPAdes: A New Genome Assembly Algorithm and Its Applications to Single-Cell Sequencing. J. Comput. Biol. 2012, 19, 455-477. [CrossRef] [PubMed]

37. Seemann, T. Prokka: Rapid Prokaryotic Genome Annotation. Bioinformatics 2014, 30, 2068-2069. [CrossRef]

38. Zhang, S.; Yin, Y.; Jones, M.B.; Zhang, Z.; Kaiser, B.L.D.; Dinsmore, B.A.; Fitzgerald, C.; Fields, P.I.; Deng, X. Salmonella Serotype Determination Utilizing High-Throughput Genome Sequencing Data. J. Clin. Microbiol. 2015, 53, 1685-1692. [CrossRef]

39. Larsen, M.V.; Cosentino, S.; Rasmussen, S.; Friis, C.; Hasman, H.; Marvig, R.L.; Jelsbak, L.; Sicheritz-Pontén, T.; Ussery, D.W.; Aarestrup, F.M.; et al. Multilocus Sequence Typing of Total-Genome-Sequenced Bacteria. J. Clin. Microbiol. 2012, 50, $1355-1361$. [CrossRef]

40. Bortolaia, V.; Kaas, R.S.; Ruppe, E.; Roberts, M.C.; Schwarz, S.; Cattoir, V.; Philippon, A.; Allesoe, R.L.; Rebelo, A.R.; Florensa, A.F.; et al. ResFinder 4.0 for predictions of phenotypes from genotypes. J. Antimicrob. Chemother. 2020, 75, 3491-3500. [CrossRef]

41. Page, A.J.; Cummins, C.A.; Hunt, M.; Wong, V.K.; Reuter, S.; Holden, M.T.G.; Fookes, M.; Falush, D.; Keane, J.A.; Parkhill, J. Roary: Rapid large-scale prokaryote pan genome analysis. Bioinformatics 2015, 31, 3691-3693. [CrossRef]

42. Doster, E.; Lakin, S.M.; Dean, C.J.; Wolfe, C.; Young, J.G.; Boucher, C.; Belk, K.E.; Noyes, N.R.; Morley, P.S. MEGARes 2.0: A database for classification of antimicrobial drug, biocide and metal resistance determinants in metagenomic sequence data. Nucleic Acids Res. 2020, 48, D561-D569. [CrossRef]

43. Carattoli, A.; Zankari, E.; García-Fernández, A.; Larsen, M.V.; Lund, O.; Villa, L.; Aarestrup, F.M.; Hasman, H. In SilicoDetection and Typing of Plasmids using PlasmidFinder and Plasmid Multilocus Sequence Typing. Antimicrob. Agents Chemother. 2014, 58, 3895-3903. [CrossRef] [PubMed]

44. Brooks, L.; Mo, K.; Mark, S. A Curated, Comprehensive Database of Plamid Sequences. Microbiol. Resour. Announc. 2019, 8, 1-2. [CrossRef]

45. Altschul, S.F.; Gish, W.; Miller, W.; Myers, E.W.; Lipman, D.J. Basic local alignment search tool. J. Mol. Biol. 1990, 215 , 403-410. [CrossRef]

46. van Bloois, L.G.; Wagenaar, J.A.; Zomer, A.L. RFPlasmid: Predicting plasmid sequences from short read assembly data using machine learning. bioRxiv 2020. [CrossRef]

47. Kaas, R.S.; Leekitcharoenphon, P.; Aarestrup, F.M.; Lund, O. Solving the Problem of Comparing Whole Bacterial Genomes across Different Sequencing Platforms. PLoS ONE 2014, 9, e104984. [CrossRef]

48. Kumar, S.; Stecher, G.; Li, M.; Knyaz, C.; Tamura, K. MEGA X: Molecular evolutionary genetics analysis across computing platforms. Mol. Biol. Evol. 2018, 35, 1547-1549. [CrossRef] [PubMed]

49. Schwarz, S.; Silley, P.; Simjee, S.; Woodford, N.; Van Duijkeren, E.; Johnson, A.P.; Gaastra, W. Editorial: Assessing the antimicrobial susceptibility of bacteria obtained from animals. J. Antimicrob. Chemother. 2010, 65, 601-604. [CrossRef] [PubMed]

50. Hong, S.; Rovira, A.; Davies, P.; Ahlstrom, C.; Muellner, P.; Rendahl, A.; Olsen, K.; Bender, J.B.; Wells, S.; Perez, A.; et al. Serotypes and Antimicrobial Resistance in Salmonella enterica Recovered from Clinical Samples from Cattle and Swine in Minnesota. PLoS ONE 2016, 11, e0168016. [CrossRef] [PubMed]

51. Shippy, D.C.; Bearson, B.L.; Holman, D.B.; Brunelle, B.W.; Allen, H.K.; Bearson, S.M. Porcine Response to a Multidrug-Resistant Salmonella enterica serovar I 4,[5],12:i:- Outbreak Isolate. Foodborne Pathog. Dis. 2018, 15, 253-261. [CrossRef] [PubMed]

52. Campos, J.; Mourão, J.; Peixe, L.; Antunes, P. Non-typhoidal Salmonella in the Pig Production Chain: A Comprehensive Analysis of Its Impact on Human Health. Pathogens 2019, 8, 19. [CrossRef] [PubMed] 
53. Mastrorilli, E.; Pietrucci, D.; Barco, L.; Ammendola, S.; Petrin, S.; Longo, A.; Mantovani, C.; Battistoni, A.; Ricci, A.; Desideri, A.; et al. A Comparative Genomic Analysis Provides Novel Insights Into the Ecological Success of the Monophasic Salmonella Serovar 4,[5],12:i:-. Front. Microbiol. 2018, 9, 715. [CrossRef] [PubMed]

54. Brunelle, B.W.; Bearson, S.M.; Bearson, B.L. Tetracycline accelerates the temporally-regulated invasion response in specific isolates of multidrug-resistant Salmonella enterica serovar Typhimurium. BMC Microbiol. 2013, 13, 202. [CrossRef] [PubMed]

55. Edrington, T.S.; Harvey, R.B.; Farrington, L.A.; Nisbet, D.J. Evaluation of Subtherapeutic Use of the Antibiotics Apramycin and Carbadox on the Prevalence of Antimicrobial-Resistant Salmonella Infection in Swine. J. Food Prot. 2001, 64, 2067-2070. [CrossRef]

56. Van Boeckel, T.P.; Brower, C.C.; Gilbert, M.; Grenfell, B.T.; Levin, S.A.S.; Robinson, T.P.; Teillant, A.A.; Laxminarayan, R.R. Global trends in antimicrobial use in food animals. Proc. Natl. Acad. Sci. USA 2015, 112, 5649-5654. [CrossRef] [PubMed]

57. Schwarz, S.; Kehrenberg, C.; Doublet, B.; Cloeckaert, A. Molecular basis of bacterial resistance to chloramphenicol and florfenicol. FEMS Microbiol. Rev. 2004, 28, 519-542. [CrossRef] [PubMed]

58. Rhouma, M.; Beaudry, F.; Thériault, W.; Letellier, A. Colistin in Pig Production: Chemistry, Mechanism of Antibacterial Action, Microbial Resistance Emergence, and One Health Perspectives. Front. Microbiol. 2016, 7, 1789. [CrossRef]

59. Zhang, J.; Chen, L.; Wang, J.; Yassin, A.K.; Butaye, P.; Kelly, P.; Gong, J.; Guo, W.; Li, J.; Li, M.; et al. Molecular detection of colistin resistance genes (mcr-1, mcr-2 and mcr-3) in nasal/oropharyngeal and anal/cloacal swabs from pigs and poultry. Sci. Rep. 2018, 8, 1-9. [CrossRef]

60. Brasil, Instrução Normativa N ${ }^{\circ}$ 45, de 22 de Novembro de 2016, Ministério da Agricultura, Pecuária e Abastecimento (MAPA). Available online: https://www.in.gov.br/materia/-/asset_publisher/Kujrw0TZC2Mb/content/id/22078290/do1-2016-11-30instrucao-normativa-n-45-de-22-de-novembro-de-2016-22078259 (accessed on 21 April 2021).

61. Li, P.; Zhu, T.; Zhou, D.; Lu, W.; Liu, H.; Sun, Z.; Ying, J.; Lu, J.; Lin, X.; Li, K.; et al. Analysis of Resistance to Florfenicol and the Related Mechanism of Dissemination in Different Animal-Derived Bacteria. Front. Cell. Infect. Microbiol. 2020, 10, 369. [CrossRef]

62. Sharma, A.; Sharma, R.; Bhattacharyya, T.; Bhando, T.; Pathania, R. Fosfomycin resistance inAcinetobacter baumanniiis mediated by efflux through a major facilitator superfamily (MFS) transporter-AbaF. J. Antimicrob. Chemother. 2017, 72, 68-74. [CrossRef]

63. Rehman, M.A.; Yin, X.; Persaud-Lachhman, M.G.; Diarra, M.S. First Detection of a Fosfomycin Resistance Gene, fosA7, in Salmonella enterica Serovar Heidelberg Isolated from Broiler Chickens. Antimicrob. Agents Chemother. 2017, 61, 1-6. [CrossRef]

64. Aghapour, Z.; Gholizadeh, P.; Ganbarov, K.; Bialvaei, A.Z.; Mahmood, S.S.; Tanomand, A.; Yousefi, M.; Asgharzadeh, M.; Yousefi, B.; Kafil, H.S. Molecular mechanisms related to colistin resistance in Enterobacteriaceae. Infect. Drug Resist. 2019, 12, 965-975. [CrossRef]

65. Chen, W.; Fang, T.; Zhou, X.; Zhang, D.-F.; Shi, X.; Shi, C. IncHI2 Plasmids Are Predominant in Antibiotic-Resistant Salmonella Isolates. Front. Microbiol. 2016, 7, 1566. [CrossRef] [PubMed]

66. Dos Santos, C.A.; Cunha, M.P.V.; Bertani, A.M.D.J.; De Almeida, E.A.; Gonçalves, C.R.; Sacchi, C.T.; De Paiva, J.B.; Camargo, C.H.; Tiba-Casas, M.R. Detection of multidrug- and colistin-resistant Salmonella Choleraesuis causing bloodstream infection. J. Antimicrob. Chemother. 2020, 75, 2009-2010. [CrossRef]

67. Mathys, D.A.; Mollenkopf, D.F.; Feicht, S.M.; Adams, R.J.; Albers, A.L.; Stuever, D.M.; Grooters, S.V.; Ballash, G.A.; Daniels, J.B.; Wittum, T.E. Carbapenemase-producing Enterobacteriaceae and Aeromonas spp. present in wastewater treatment plant effluent and nearby surface waters in the US. PLoS ONE 2019, 14, e0218650. [CrossRef] [PubMed]

68. Prussing, C.; Snavely, E.A.; Singh, N.; Lapierre, P.; Lasek-Nesselquist, E.; Mitchell, K.; Haas, W.; Owsiak, R.; Nazarian, E.; Musser, K.A. Nanopore MinION Sequencing Reveals Possible Transfer of blaKPC-2 Plasmid Across Bacterial Species in Two Healthcare Facilities. Front. Microbiol. 2020, 11, 1-11. [CrossRef] [PubMed]

69. Keefer, A.B.; Xiaoli, L.; M'Ikanatha, N.M.; Yao, K.; Hoffmann, M.; Dudley, E.G. Retrospective whole-genome sequencing analysis distinguished PFGE and drug-resistance-matched retail meat and clinical Salmonella isolates. Microbiology 2019, 165, 270-286. [CrossRef]

70. Schürch, A.; Arredondo-Alonso, S.; Willems, R.; Goering, R. Whole genome sequencing options for bacterial strain typing and epidemiologic analysis based on single nucleotide polymorphism versus gene-by-gene-based approaches. Clin. Microbiol. Infect 2018, 24, 350-354. [CrossRef]

71. Kich, J.D.; Coldebella, A.; Morés, N.; Nogueira, M.G.; Cardoso, M.; Fratamico, P.M.; Call, J.E.; Fedorka-Cray, P.; Luchansky, J.B. Prevalence, distribution, and molecular characterization of Salmonella recovered from swine finishing herds and a slaughter facility in Santa Catarina, Brazil. Int. J. Food Microbiol. 2011, 151, 307-313. [CrossRef]

72. Mathew, A.G.; Cissell, R.; Liamthong, S. Antibiotic Resistance in Bacteria Associated with Food Animals: A United States Perspective of Livestock Production. Foodborne Pathog. Dis. 2007, 4, 115-133. [CrossRef] 